\title{
Design and Optimization of Vertical Axis Wind Turbines Using QBlade
}

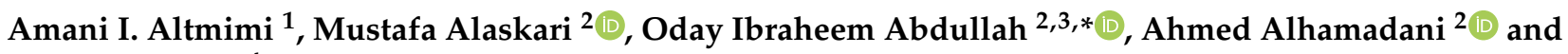 \\ Jenan S. Sherza ${ }^{4}$ \\ 1 College of Energy and Environmental Sciences, Al-Karkh University of Science, Baghdad 10003, Iraq; \\ dr.amani_altmimi@kus.edu.iq \\ 2 Department of Energy Engineering, University of Baghdad, Baghdad 10071, Iraq; \\ mustafa.alaskari@coeng.uobaghdad.edu.iq (M.A.); ahmed@coeng.uobaghdad.edu.iq (A.A.) \\ 3 Department of Mechanics, Al-Farabi Kazakh National University, Almaty 050038, Kazakhstan \\ 4 Air Conditioning Techniques Engineering Department, Al-Esraa University College, Baghdad 10068, Iraq; \\ janashaker87@gmail.com \\ * Correspondence: oday.abdullah@tuhh.de
}

check for updates

Citation: Altmimi, A.I.; Alaskari, M.; Abdullah, O.I.; Alhamadani, A.;

Sherza, J.S. Design and Optimization of Vertical Axis Wind Turbines Using QBlade. Appl. Syst. Innov. 2021, 4, 74. https://doi.org/10.3390/asi4040074

Academic Editors: Emmanuel Karapidakis and Teen-Hang Meen

Received: 18 June 2021

Accepted: 28 September 2021

Published: 9 October 2021

Publisher's Note: MDPI stays neutral with regard to jurisdictional claims in published maps and institutional affiliations.

Copyright: (c) 2021 by the authors. Licensee MDPI, Basel, Switzerland. This article is an open access article distributed under the terms and conditions of the Creative Commons Attribution (CC BY) license (https:// creativecommons.org/licenses/by/ $4.0 /)$.

\begin{abstract}
Wind energy is considered one of the most important sources of renewable energy in the world, because it contributes to reducing the negative effects on the environment. The most important types of wind turbines are horizontal and vertical axis wind turbines. This work presents the full details of design for vertical axis wind turbine (VAWT) and how to find the optimal values of necessary factors. Additionally, the results shed light on the efficiency and performance of the VAWT under different working conditions. It was taken into consideration the variety of surrounding environmental conditions (such as density and viscosity of fluid, number of elements of the blade, etc.) to simulate the working of vertical wind turbines under different working conditions. Furthermore, the effect of the design factors was investigated such as the number and size of the blades on the behavior and performance of VAWT. It was assumed that the vertical wind blade works in different sites of Iraq. QBlade software (Version 8) was used to achieve the calculations and optimization processes to obtain the optimal design of vertical axis wind turbines that is suitable for the promising sites. The results proved that accurate results can be obtained by using QBlade software.
\end{abstract}

Keywords: vertical axis wind turbine; power generation; aerodynamic analysis

\section{Introduction}

Recently, there are many researchers from the academic and industry sectors that have turned their attention to developing the vertical axis wind turbine (VAWT), where the main advantage of the VAWTs is capturing the wind from any direction. This is considered a significant feature in urban areas, where it is difficult to know the major direction of wind due to the presence of a high number of obstacles (natural and unnatural) and flowdirecting influences. In the urban areas, a new idea has been introduced to increase the production of clean energy, by installation of the small power vertical axis wind turbines on the roof of high constructions. There is another method that encouraged to build the offshore vertical axis wind turbines with huge sizes. Figure 1 shows different typical vertical axis wind turbines.

On the other hand, many other problems appeared during the design and after installation of the vertical axis wind turbines such as unbalance, vibration and difficulty to expect the output power. Extensive experimental research was achieved on the axial wind turbine in the field in addition to developing specialist software that led to introducing a new model by Ion Paraschivoiu. This model was called the Double-Multiple Stream tube (DMS) model. Two parameters were adopted and used in the circular path that related to the blade and extraction of energy. These parameters were introduced by the 
following terms in the upstream and downstream rotor halves in relation to the rotational axes [1]. The theoretical approach was applied using QBlade software to investigate and analyze different types of airfoils such as DU-06-W200, NACA 0018, and NACA 0021. The produced power assuming different configurations of the twist angle $\left(\psi=30^{\circ}, 60^{\circ}, 90^{\circ}\right.$, and $120^{\circ}$ ) for $1 \mathrm{~kW}$ axial wind turbine was analyzed. The extracted energy by the wind blade when reducing the fluid velocity was also determined. Acceptable results were obtained based on the principle of Double-Multiple Stream tube model (DMS). Additionally, it has been found that reliable results can be obtained for different configurations of the axial wind turbine using blade design simulation tool, where the cost and time will be much higher when using the experimental work to obtain the same results [2].

The main objective in the design of wind turbine is to obtain the optimal solution of the VAWT based on the new design approach to enhance the extracted power by minimizing the changes excluding the movable parts. The influences of the change in the aspect ratios as well as the aerodynamic shape using a classical Darrieus rotor with SANDIA shape was studied. NACA0018 and NACA0012 blade profiles were used to enhance the characteristics of the rotor. It was found that each shape of the aerodynamic and aspect ratio has a significant impact on the output power. These results encouraged more researchers to investigate in this area to enhance the performance and output power of the vertical axis wind turbine [3]. Previous studies aimed to obtain the optimal design of the vertical axis wind turbine using QBlade software. It was found that the main advantage of using this software was analyzing the velocity of wind that comes from different directions with high accuracy, where the installation of generators and connecting the electrical cables for this kind of wind turbine is easier and of less cost compared with the horizontal wind turbine.

The wide range of results and the high accuracy led to making QBlade software to be a significant design tool to analyze different kinds of wind turbines [4]. This software was used to study the effect of thickness of the airfoil blade on the behavior and performance of the vertical axis wind turbines. The results can be presented by using different kinds of plots; therefore, it can be found that the optimal design is based on the different aerodynamic governing features. Additionally, the dynamic influences on the blade section lift (propeller), coefficients of pitching moment and the drag force can be studied. It was concluded that the thicker profiles are more efficient than thinner profiles. It was shown that the VAWT of eggbeater types with thicker profiles is more suitable than thinner profiles because of the lift forces [5]. There are other researchers [6-12] who studied that rotating blade from a different point of view, where they investigated the stresses and vibration characteristics of a rotating blade that works under different kinds of conditions in general and especially the wind speed.

The finite element method was used to analyze the stresses and deformations for the straight blade of wind turbine (H-Darrieus) with a power rating of $2.5 \mathrm{~kW} \mathrm{[13].} \mathrm{The}$ 3D model of a wind turbine blade was developed using SolidWorks and computer-aided design (CAD) softwares. No structural failures were expected based on the obtained simulation of the two systems because the safety factors for both cases were high enough. It was investigated that the torsional aero-elasticity of the blade of the H-type VAWT are subjected to stall as well as post-stalling conditions under different Reynolds regimes [14]. A model has been proposed based on the combination of the Double Multi-Stream tubes (DMST) model and the nonlinear multi-criteria $\mathrm{Cl}-\alpha$ equations that are used to simulate the aerodynamics problem. The main findings demonstrated that the blade undergoes aeroelastic torsion between $+7^{\circ}$ and $+12^{\circ}$ at higher TSR values and between $-4^{\circ}$ and $+19^{\circ}$ at lower TSR values. As a result, running the blade at high TSR values is supposed to extend its lifetime. A fully automatic procedure for optimizing the VAWT cross-section airfoil has been developed and demonstrated [15]. The goal was to increase the torque while placing traditional restrictions on the structure of wind turbines, such as tip speed ratio, power, and blade profile. The simplicity and functionality of the modular design and simulation system enabled it to be conveniently integrated with the parallel differential evolution algorithms that were used to produce an efficient blade configuration to maximize the 
performance of wind turbine. The effect of blade number on drag type VAWT performance was examined [16]; 3-blade, 5-blade, and 6-blade were used to optimize the blade width for each VAWT at optimum power efficiency. Different numbers of blades were used for the turbine with the same radius and inlet wind speed. It was found that the reliability of the wind turbine and the maximum performance increased significantly.
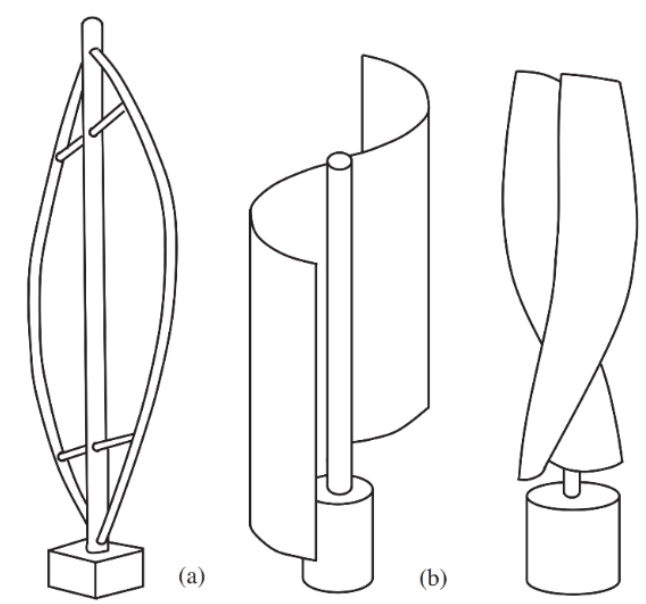

(c)
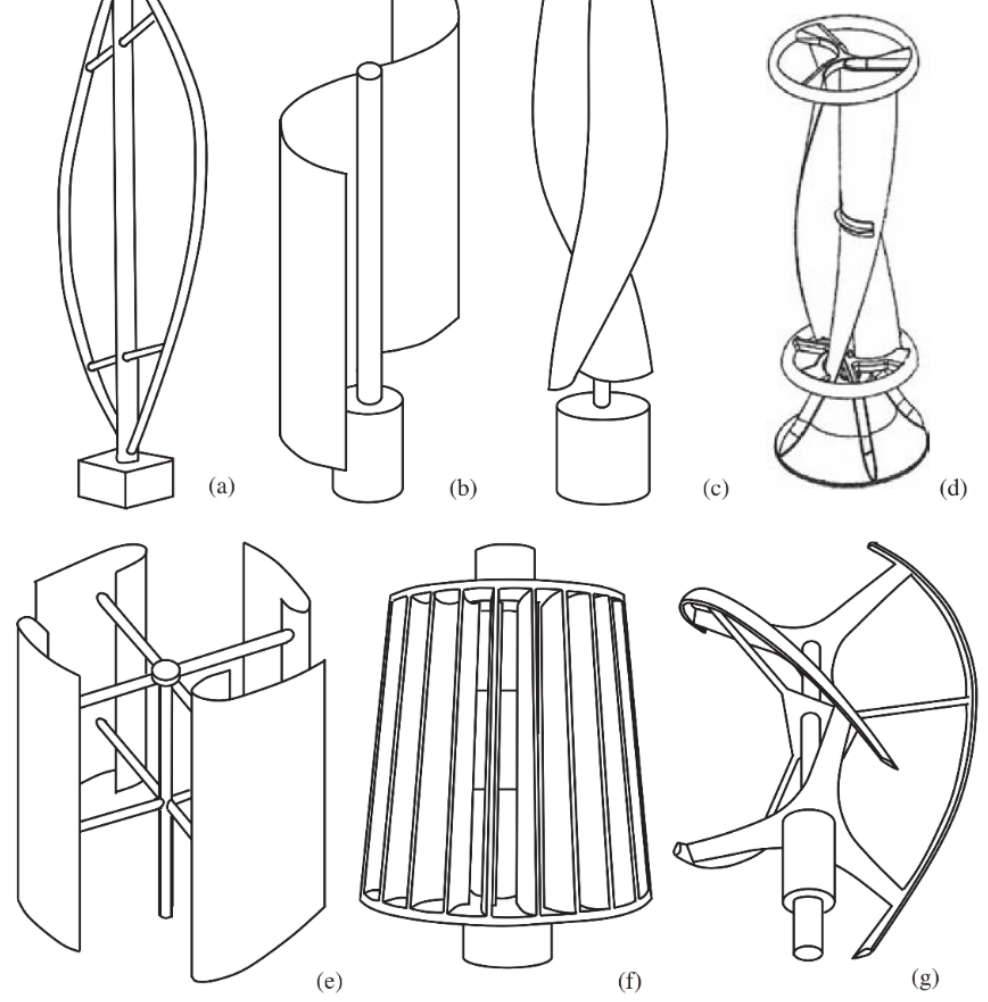

Figure 1. Several typical types of vertical-axis wind turbines: (a) Darrius; (b) Savonius; (c) Solarwind; (d) Helical; (e) Noguchi; (f) Maglev; (g) Cochrane [17].

Chen et al. [18] presented a new model of electric load forecasting, where the fuzzy c-means clustering was used to find the clustering center. Additionally, the Least Square Support Vector Machine (LSSVM) approach was applied to simulate the optimized resultant series. The results were verified with the experimental results. It was found that the proposed GHSA-FTS-LSSVM model effectively generates more accurate predictive results.

\section{Geometric Parameters of the Vertical Axis Wind Turbine}

In this section, all details of the geometrical parameters of the selected VAWT will be presented. The parameters of the rotor blades and the wind turbine design parameters are listed in Tables 1 and 2, respectively. The following specification of VAWT is selected to perform the analysis using QBlade software. 
Table 1. VAWT specifications.

\begin{tabular}{cc}
\hline Parameters & Specifications \\
\hline Axis of rotation & Vertical \\
Turbine height & $0.562 \mathrm{~m}$ \\
Rotor radius & $0.22 \mathrm{~m}$ \\
Foil type & NACA 4418 \\
No. of blades & 3 \\
Swept area & $0.25 \mathrm{~m}^{2}$ \\
Cut-in wind speed & $2 \mathrm{~m} / \mathrm{s}$ \\
Cut out wind speed & $16 \mathrm{~m} / \mathrm{s}$ \\
Wind speed range & $1-20 \mathrm{~m} / \mathrm{s}$ \\
Rotational speed range RPM & $200-500 \mathrm{RPM}$ \\
\hline
\end{tabular}

Table 2. Vertical axis wind blade profile design for different sections of the blade.

\begin{tabular}{cccccc}
\hline No. & Height $(\mathbf{m})$ & Chord $(\mathbf{m})$ & Radius $(\mathbf{m})$ & Optimized Radius $(\mathbf{m})$ & Foil \\
\hline 1 & 0 & 0.01 & 0.22 & 0.01 & NACA 4418 \\
2 & 0.031 & 0.01 & 0.22 & 0.0553 & NACA 4419 \\
3 & 0.062 & 0.01 & 0.22 & 0.1007 & NACA 4420 \\
4 & 0.094 & 0.01 & 0.22 & 0.1476 & NACA 4421 \\
5 & 0.125 & 0.01 & 0.22 & 0.1929 & NACA 4422 \\
6 & 0.156 & 0.01 & 0.22 & 0.2306 & NACA 4423 \\
7 & 0.188 & 0.01 & 0.22 & 0.2545 & NACA 4424 \\
8 & 0.219 & 0.01 & 0.22 & 0.2691 & NACA 4425 \\
9 & 0.25 & 0.01 & 0.22 & 0.2772 & NACA 4426 \\
10 & 0.281 & 0.01 & 0.22 & 0.28 & NACA 4427 \\
11 & 0.312 & 0.01 & 0.22 & 0.2772 & NACA 4428 \\
12 & 0.344 & 0.01 & 0.22 & 0.2687 & NACA 4429 \\
13 & 0.375 & 0.01 & 0.22 & 0.2539 & NACA 4430 \\
14 & 0.406 & 0.01 & 0.22 & 0.2306 & NACA 4431 \\
15 & 0.438 & 0.01 & 0.22 & 0.1915 & NACA 4432 \\
16 & 0.469 & 0.01 & 0.22 & 0.1461 & NACA 4433 \\
17 & 0.5 & 0.01 & 0.22 & 0.1007 & NACA 4434 \\
18 & 0.531 & 0.01 & 0.22 & 0.0553 & NACA 4435 \\
19 & 0.562 & 0.01 & 0.22 & 0.01 & NACA 4436 \\
\hline
\end{tabular}

The details of design parameters used to build the models of the blade are shown in Table 2. Each blade was divided into 19 parts that represent the airfoil section side facing inwards.

\section{Theoretical Background}

The fundamental equations that were used to build the mathematical model of the VAWT will be presented with details in this section. The relative velocity of the blade can be written as follows:

$$
\omega=V_{\infty}-R_{w}
$$

where $V_{\infty}$ is undisturbed air velocity, $R_{w}$ is the blade velocity at equator radius and $\omega$ is speed of rotation for the blades.

The significant velocities when using the DMS calculation approach are:

1. $V_{\infty}$ : The inflow velocity of the undisturbed freestream flow.

2. $V$ : The upwind induced velocity that occurred owing to the extraction energy from blades at upstream rotor half.

3. $V_{e}$ : Equilibrium velocity that appeared in the plane between up-and downstream rotor half, which denotes the velocity of upstream rotor disk (wake) and the inflow velocity of the downstream rotor disk.

4. $\quad V^{\prime}$ : The downwind induced velocity that occurred owing to the extraction energy of blades in the downstream rotor half. 
5. $V^{\prime \prime}$ : The wake velocity of the complete double disk.

The first step of the calculations process is to determine these mentioned velocities, and then the parameters of extraction energy in the up-and downstream rotor half can be defined as follows:

$$
\begin{aligned}
& u=\frac{V}{V_{\infty}} \\
& u^{\prime}=\frac{V^{\prime}}{V_{e}}
\end{aligned}
$$

The global tip speed ratio is the relative speed of rotation of the (VAWT):

$$
\mathrm{TSR}=\frac{R_{w}}{V_{\infty}}
$$

Additionally, the simulation of the turbine enables the determination of the inflow wind profile. There are three potential options which are:

1. Uniform velocity profile (like the simulation of a rotor);

2. Power law:

$$
V_{\infty}(z)=v_{r e f}\left(\frac{z}{z_{r e f}}\right)^{\alpha}
$$

where $V_{\text {ref }}$ is the simulated wind speed, $Z_{r e f}$ is the equator of the turbine and $\alpha$ is the roughness exponent.

3. Logarithmic approach:

$$
V_{\infty}(z)=v_{r e f}\left(\frac{\log \left(\frac{z}{z_{0}}\right)}{\log \left(\frac{z_{r e f}}{z_{0}}\right)}\right)^{\alpha}
$$

where $Z_{0}$ is depending on the surroundings of the wind turbine (e.g., $Z_{0}=0.2 \mathrm{~mm}$ for open water and $Z_{0}=2 \mathrm{~m}$ for highly built-up areas).

\section{Power Generation Calculations}

Power generated by the wind turbine is influenced at a particular time mostly by air mass elevated of the rotor blades. An increase in tip speed ratio leads to a decrease in the mass being lifted and will affect the power output. The maximum power that the turbine could capture depends on turbine design including blade airfoil, and pitch angle. Figure 2 shows the details of the developed approach used in this research paper to analyze and optimize the vertical axial wind turbine.

The produced power by the wind turbine is determined based on the power coefficient $\left(C_{P}\right)$ including the tip speed ratio $(\lambda)$ and pitch angle $(\beta)$ parameters. The tip speed ratio $\lambda$ will often adjust over time because it is determined by the turbine rotor's angular velocity. The feedback from the turbine rotor to the ratio of tip speed can be created in a closed loop.

The available kinetic energy in the wind that can be converted to mechanical energy is not exceeding $59 \%$ of the total value (theoretically), as specified in the law of Betz, where the power extracted practically is typically less than $45 \%$ of the available energy. By considering the field swept by VAWTs, the area $A=r l$, velocity of air $=v$, length of the VAWT blade $=l$, density of the air $=\rho$, and theoretical Betz limit $C p=0.59$ of the output power. Then the maximum power $(P)$ that is available can be calculated as follows:

$$
P_{\text {available. } \max }=\frac{1}{2} \rho A v^{3} C p
$$

where $A=$ swept area of the rotating blades, $\rho=$ air density, $V=$ air velocity and $C p=$ Power coefficient. 
Rather than using an alternator or generator that is readily available, a permanent magnet generator is built according to requirement. The generator is equipped with a multi-stage and is used to maximize the output of the generator with the same size of the rotor. Each stage is composed of 12 coils and 24 magnets.

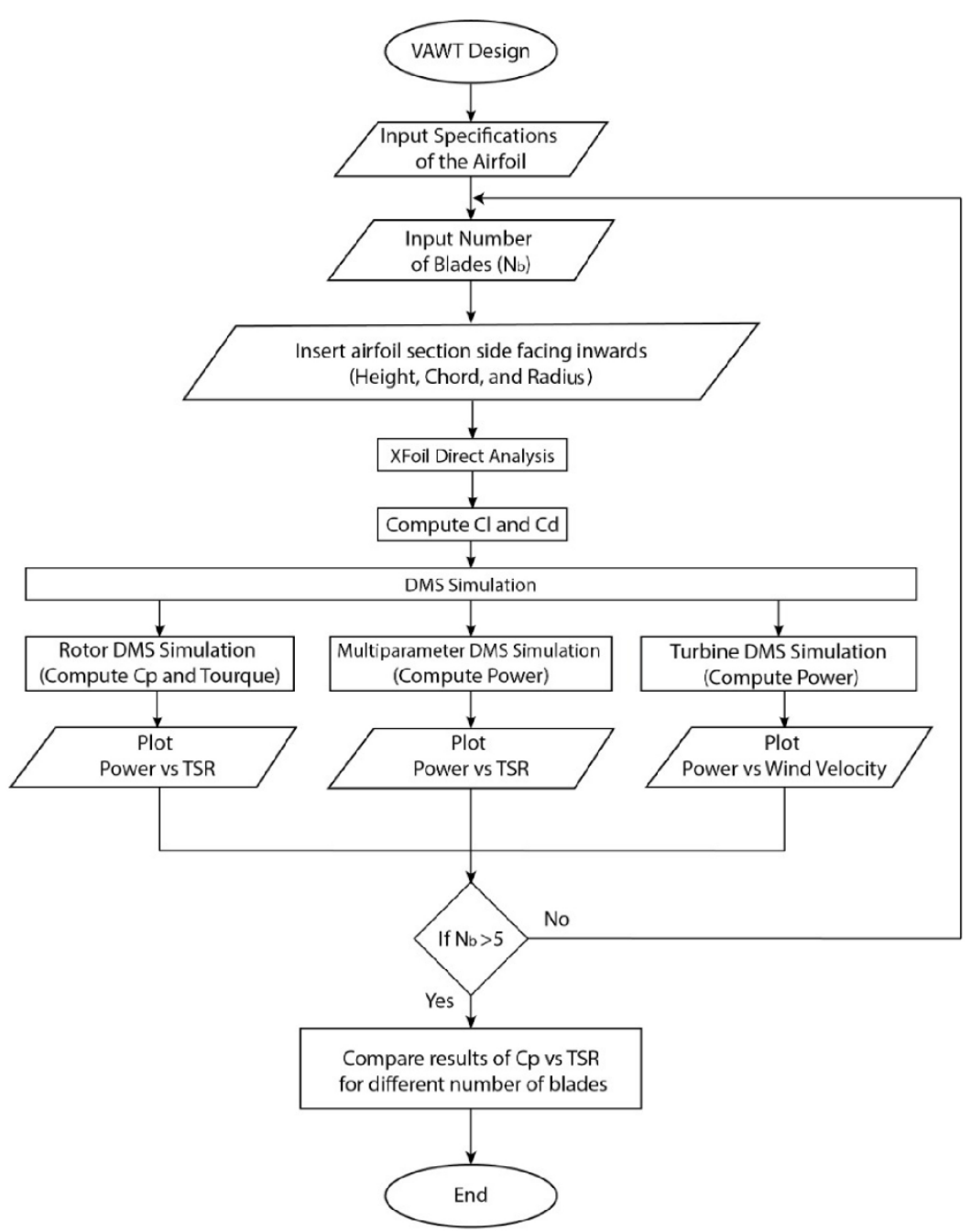

Figure 2. Flowchart of the developed approach to analyze and optimize the vertical axial wind turbine.

\section{Results and Discussions}

In order to obtain the model of the rotor and the design for different VAWT types, the NACA4418 for the blade was selected as shown in Figure 3. Each blade divided to a finite number of blade sections. For each blade section, the design parameters of circumferential position, vertical position, radial position, length of the chord, and type of airfoil was introduced. All airfoil sections of straight blades have the same radius and circumferential position. In order to enhance the design of the blade of the vertical axis wind turbine and decrease the time consumption to find the results, scaling and optimization functionalities are used as illustrated in Figure 4. These parameters are height scaling, height shifting, chord scaling, radius scaling, and twist scaling to speed up the rotor modification. The analyses were performed on the blade of the turbine within range (1 to 10 of tip speed ratio $\lambda$ ). In this analysis, a constant velocity of $7 \mathrm{~m} / \mathrm{s}$ was used, while the rotation of the rotor was varied concerning $\lambda$. As a result, the power coefficient and torque values vs. various tip speed ratios can be seen in Figures 5 and 6, respectively. At low $\lambda$, the rotor does not spin and therefore, under such conditions, it cannot obtain power from the wind. There 
would be an acceptable value at the maximum power which is derived between $\lambda=1$ and $\lambda=10$. This would be the situation within the average speed of the rotor which is $2 / 3$ of the wind speed in compliance with the Betz law. At the high value of $\lambda$, the rotor runs faster, and the chance to extract energy from the wind will decrease because the mass transports (wind) through the rotor will be reduced.

The optimum values of the design parameters were selected as inputs in the algorithm used in the software (DMS algorithm). During the computation process, it was assumed that the velocity of a free stream would be unified and it was used for the normalized dimensions of the rotor (height and radius).

\begin{tabular}{|l|l|}
\hline 3 Blades VAWT & \\
& \\
& $0.562 \mathrm{~m}$ \\
& $0.500 \mathrm{~m}$ \\
$0.469 \mathrm{~m}$ \\
$0.438 \mathrm{~m}$ \\
$0.406 \mathrm{~m}$ \\
$0.375 \mathrm{~m}$ \\
$0.344 \mathrm{~m}$ \\
$0.312 \mathrm{~m}$ \\
$0.281 \mathrm{~m}$ \\
$0.250 \mathrm{~m}$ \\
$0.219 \mathrm{~m}$ \\
$0.188 \mathrm{~m}$ \\
$0.156 \mathrm{~m}$ \\
$0.125 \mathrm{~m}$ \\
$0.094 \mathrm{~m}$ \\
$0.062 \mathrm{~m}$ \\
\\
& $0.031 \mathrm{~m}$ \\
& $0.000 \mathrm{~m}$
\end{tabular}

Figure 3. Design of 3 blades of VAWT.

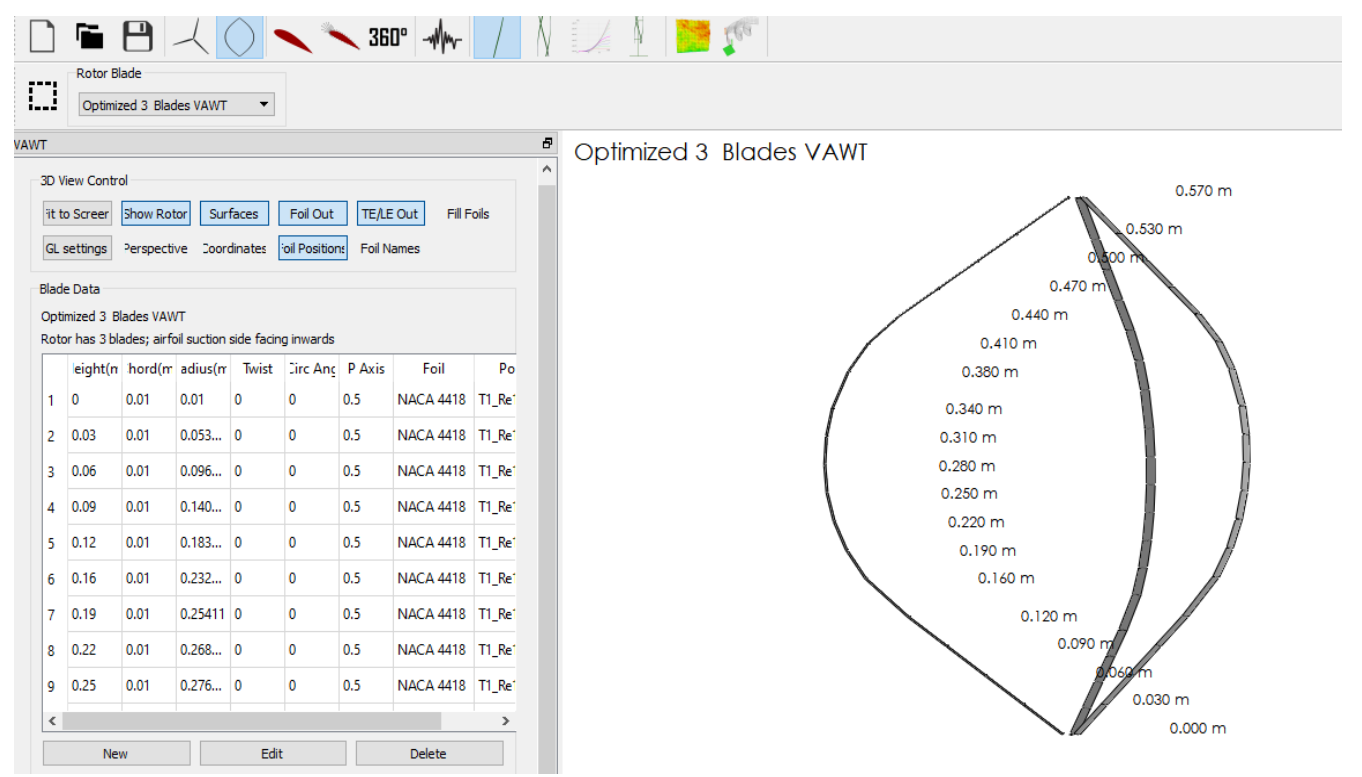

Figure 4. The details of the blade optimization process. 


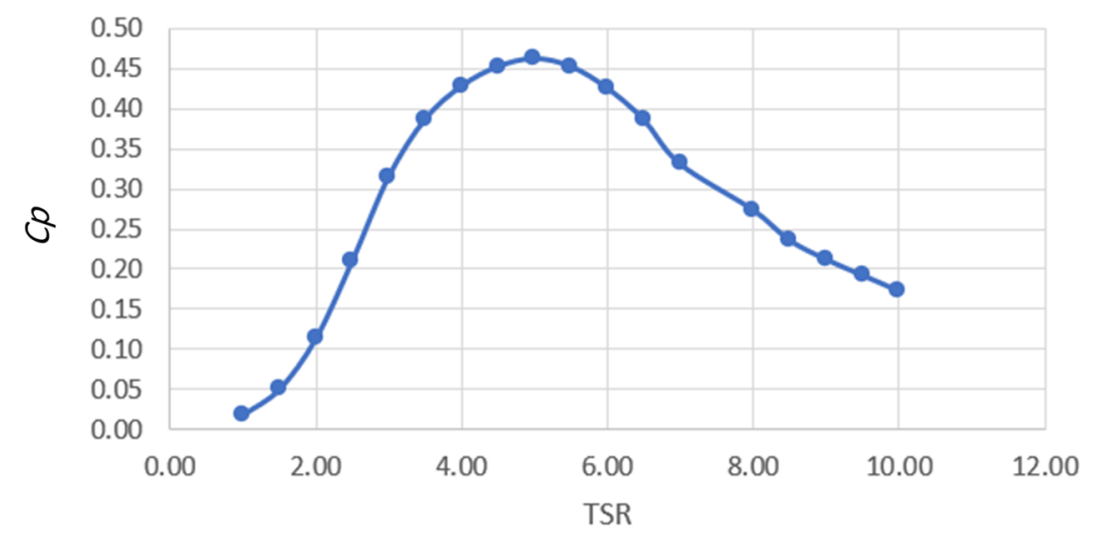

Figure 5. Coefficient of performance $(C p)$ vs. tip speed ratio (TSR) for 3 blades of VAWT.

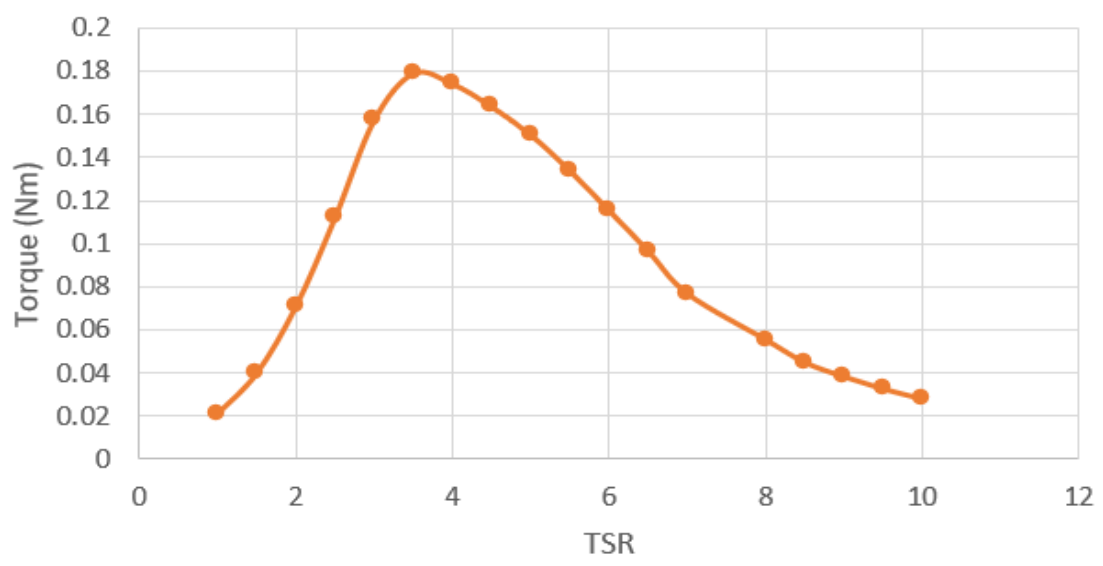

Figure 6. Torque vs. tip speed ratio (TSR) for 3 blades of VAWT.

Furthermore, the graph type of DMS simulation is available to determine the multiparameters as shown in Figure 7. Power is not only dependent on the tip speed ratio but also on the rotational speed and pitch angle. For the range that started from 200 to $500 \mathrm{rpm}$ with an increment of 100 of tip speed ratio TSR, four groups of results were obtained. It can be noticed that when power increased, the TSR increased, too. The power versus the wind speed was presented for 3 blades of VAWT using the simulation operation as shown in Figure 8.

A rotor blade should be presented in the runtime database and parameters (rotor blade, cut-in and out wind speed, turbine offset, fixed and variable losses) of the wind that is to be specified to define the wind turbine. Comparisons between 3, 4, and 5 blades of VAWT rotor simulation were made as shown in Figure 9. It was noticed that the coefficient of performance $C p$ increased when the number of blades increased, too. The maximum values of $C p$ were observed at TSR $=5$ for the 3 blades (VAWT), and at TSR $=4.5$ for the 4 blades (VAWT), while the maximum $C p$ recorded for the 5 blades of VAWT was at TSR $=4$. Additionally, it can be noticed that when using 5 blades, the values of $C p$ (after maximum value) are decreased until TSR $=6$ and then increased. While for the other cases ( 3 and 4 blades), the values of $C p$ decreased gradually. 


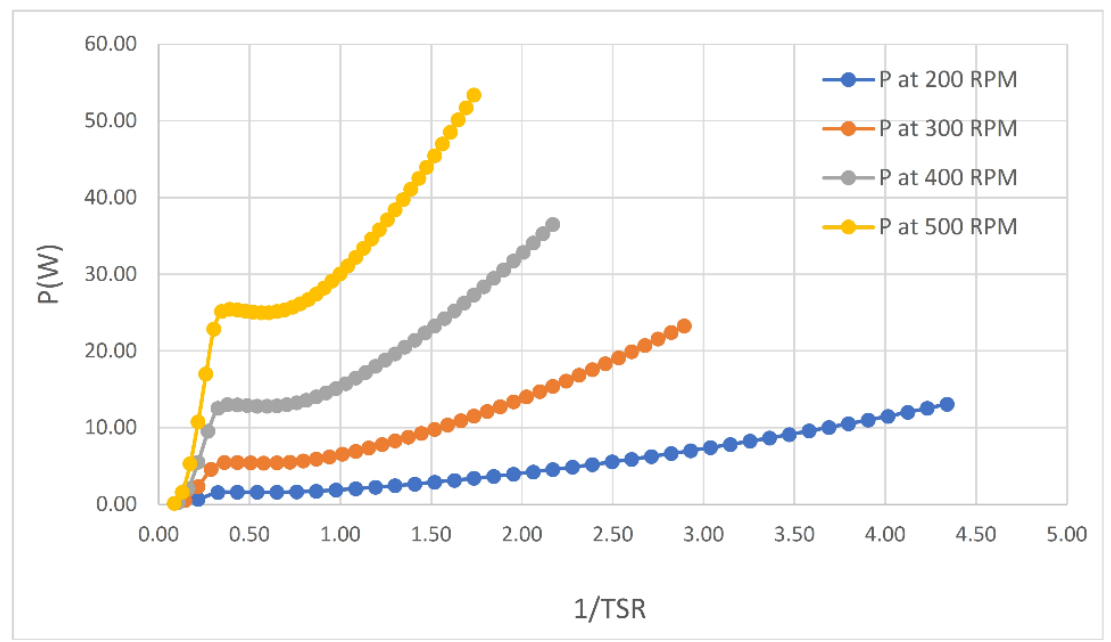

Figure 7. Power $(W)$ vs. 1/tip speed ratio (TSR) for 3 blades of VAWT with different speed using multiparameter DMS simulation in QBlade.

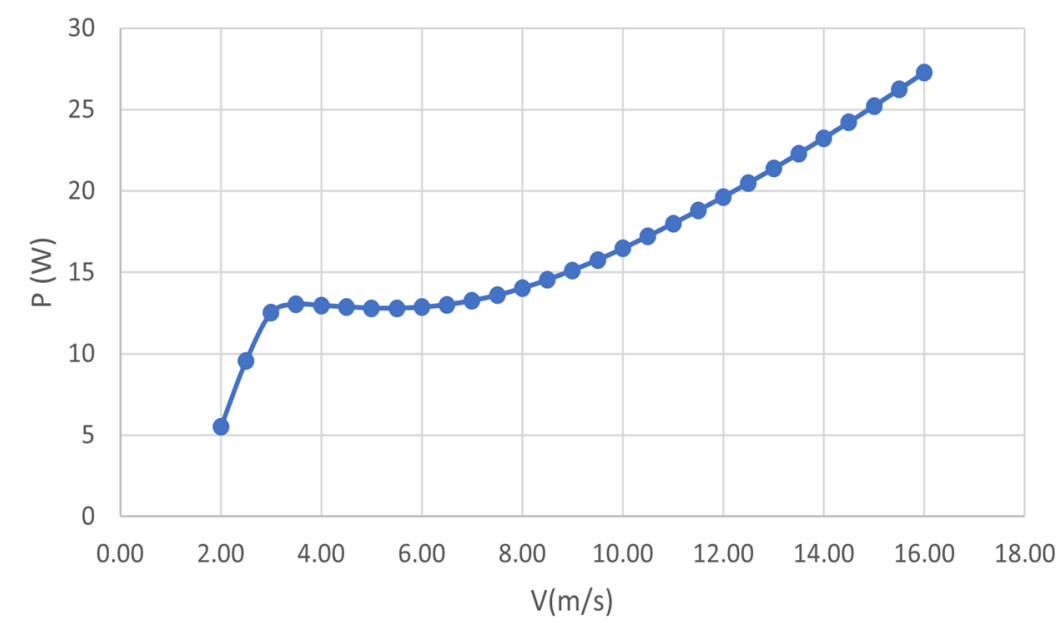

Figure 8. Power $(W)$ vs. wind speed $(\mathrm{m} / \mathrm{s})$ for 3 blades of VAWT.

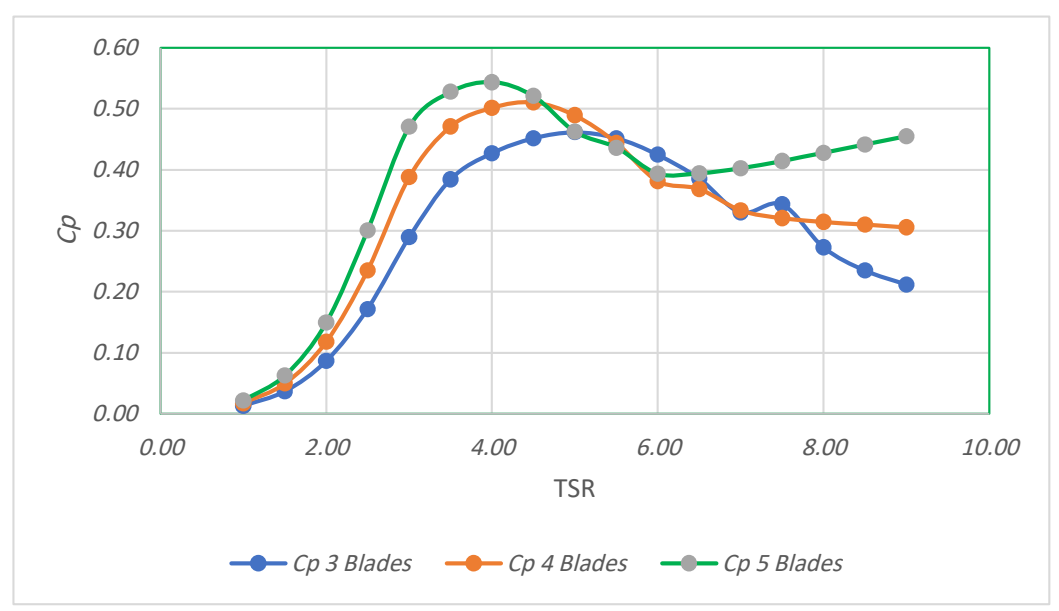

Figure 9. Coefficient of performance (Cp) vs. tip speed ratio (TSR) for 3, 4 and, 5 blades of VAWT.

Figure 10 shows the change of lift coefficient with drag coefficient for 3 blades of VAWT using XFOIL direct analysis in QBlade. 


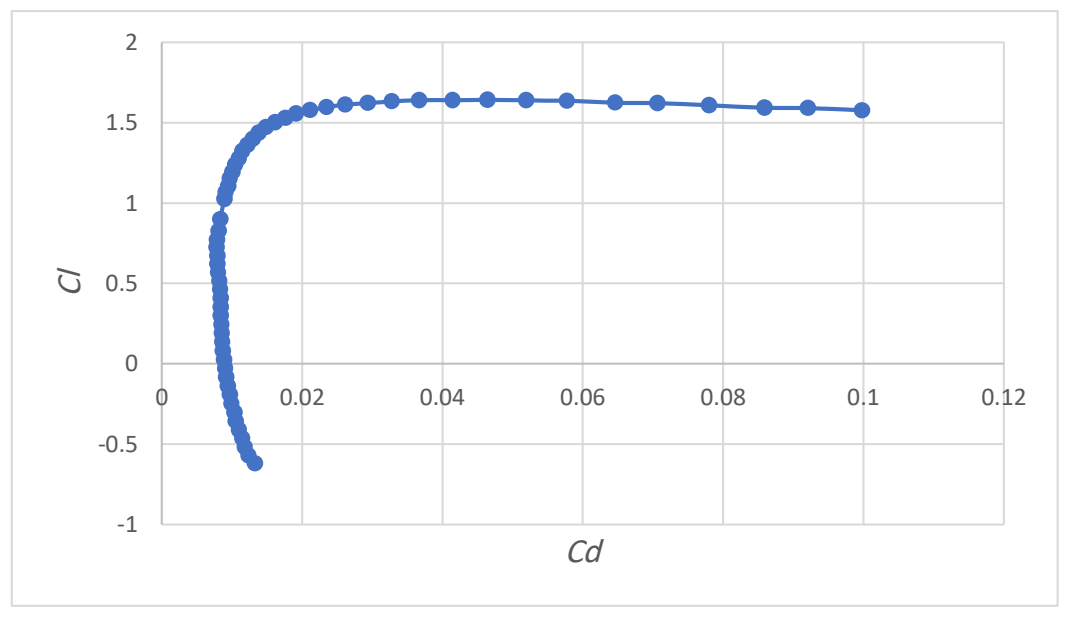

Figure 10. Variation of lift coefficient $(C l)$ vs. drag coefficient $(C d)$ for 3 blades of VAWT.

\section{Conclusions and Remarks}

In this research paper, the full details were presented to obtain the optimal design to enhance the output power of the vertical axis wind turbine using QBlade software. The study focused mainly on finding the optimal values of the design parameters of VAWT blade airfoil. The helical blade is produced using the sub-module blade design and optimized using NACA4418 blade airfoil. Significant influence of the number of blades on the performance of the vertical axis wind turbine was found. It was concluded that 4 blades of turbine rotor are more efficient than the rotor turbine with 3 blades of rotor. On the other hand, the 5-blade turbine rotor showed better efficiency than the 3-blade model, but it failed for the condition of TSR greater than 9. Additionally, it was found that the power increased at the high rotational speed (500 rpm). The maximum power coefficient of the 3 blades VAWT was identified at TSR $=5$.

This work is considered the first step in the project to study and analyze the vertical axis wind turbines, and it will be followed by other research that will study other types and designs of wind turbines in different promised sites.

Author Contributions: Funding acquisition, M.A. and O.I.A.; Investigation, A.A.; Methodology, A.I.A., O.I.A. and J.S.S.; Software, A.I.A. All authors have read and agreed to the published version of the manuscript.

Funding: This research received no external funding.

Institutional Review Board Statement: Not applicable.

Informed Consent Statement: Not applicable.

Data Availability Statement: Data is contained within the article.

Conflicts of Interest: The authors declare no conflict of interest.

\section{References}

1. Marten, D.; Wendler, J. QBlade Guidelines; v0.6; The Technical University of Berlin: Berlin, Germany, 2013 ; p. 49.

2. Jagtap, M.; Navale, L. Twist angle analysis of helical vertical axis wind turbine VAWT using Q-Blade. Int. J. Res. Publ. Eng. Technol. 2017, 3, 2454-7875.

3. Ionescu, R.D.; Vlase, S.; Ivanoiu, M. Rotor design for vertical axis wind turbines, suitable for urban seashore environment or naval industry implementation (numerical methods and analytical calculus). J. Ind. Des. Eng. Graph. 2014, 9, 83-86.

4. Sharma, R.; Patel, B. Design and simulation of Darrieus (Eggbeater) type vertical axis wind turbine using open-source software Q blade. Int. J. Innov. Res. Sci. Technol. 2015, 1, 162-169.

5. Sharma, R.; Patel, B. Effect of thickness of blade profile on performance of darrieus (eggbeater) type vertical axis wind turbine using open-source software Q Blade. Int. J. Technol. Res. Eng. 2015, 2, 1987-1990.

6. Abdullah, O.I. A Finite element analysis for the damaged rotating composite blade. Al-Khwarizmi Eng. J. 2011, 7, 56-75. 
7. Abdullah, O.I. Vibration analysis of rotating pre-twisted cantilever plate by using the finite element method. J. Eng. 2009, 15, 3492-3505.

8. Al-Ameen, E.S.; Abdullah, O.I. Vibration of non-rotating blades experimental and numerical investigation. J. Eng. Sustain. Dev. 2007, 11, 113-124.

9. Abdullah, O.I. Dynamic analysis of rotating cantilever plates. Al-Khwarizmi Eng. J. 2006, 2, 46-60.

10. Khazem, E.A.; Abdullah, O.I.; Sabri, L.A. Steady-state and vibration analysis of a Wind PACT 1.5-MW turbine blade. FME Trans. 2019, 47, 195-201. [CrossRef]

11. Zuheir, S.; Abdullah, O.I.; Al-Maliki, M. Stress and vibration analyses of the wind turbine blade (A NREL 5MW). J. Mech. Eng. Res. Dev. 2019, 42, 14-19. [CrossRef]

12. Gumilar, L.; Kusumawardana, A.; Prihanto, D.; Wicaksono, H. Analysis Performance Vertical Axis Wind Turbine Based on Pitch Angle to Output Power. In Proceedings of the 2019 IEEE International Conference on Information and Communications Technology (ICOIACT), Yogyakarta, Indonesia, 24-25 July 2019; pp. 767-772.

13. Fateh, F.; Cherif, K. Structural strength analysis and fabrication of a straight blade of an H-Darrieus wind turbine. J. Appl. Comput. Mech. 2021, 7. [CrossRef]

14. Shams, S.; Molaei, A.; Mirzavand, B. Torsional aeroelasticity of a flexible VAWT blade using a combined aerodynamic method by considering post-stall and local reynolds regime. J. Appl. Comput. Mech. 2020, 6, 757-776.

15. Carrigan, T.J.; Dennis, B.H.; Han, Z.X.; Wang, B.P. Aerodynamic shape optimization of a vertical-axis wind turbine using differential evolution. ISRN Renew. Energy 2012, 2012, 1-16. [CrossRef]

16. Zheng, M.; Li, Y.; Teng, H.; Hu, J.; Tian, Z.; Zhao, Y. Effect of blade number on performance of drag type vertical axis wind turbine. Appl. Sol. Energy 2016, 52, 315-320. [CrossRef]

17. Wei, T. Wind Power Generation and Wind Turbine Design; WIT Press: Ashurst, UK, 2010.

18. Chen, Y.H.; Hong, W.-C.; Shen, W.; Huang, N.N. Electric load forecasting based on a least squares support vector machine with fuzzy time series and global harmony search algorithm. Energies 2016, 9, 70. [CrossRef] 